\title{
FFF Forstarets
}

forskningsinstitutt

\section{Vessel tracking using Automatic Identification System data in the Arctic}

Torkild Eriksen and Øystein Olsen

ShipArc2015

Malmø, 26 August 2015 


\section{Content}

- Use of SAT-AIS data from AISSat-1 and AISSat-2 for trend analysis as well as situational awareness

- Number of ships per month north of $67^{\circ}$

- In the entire area north of $67^{\circ}$ (Arctic)

- In sectors of $45^{\circ}$ longitude

- By flag state

- By ship type

- Number of ships through the Northeast Passage

- Ship densities and tracks

- Quality of SAT-AIS service

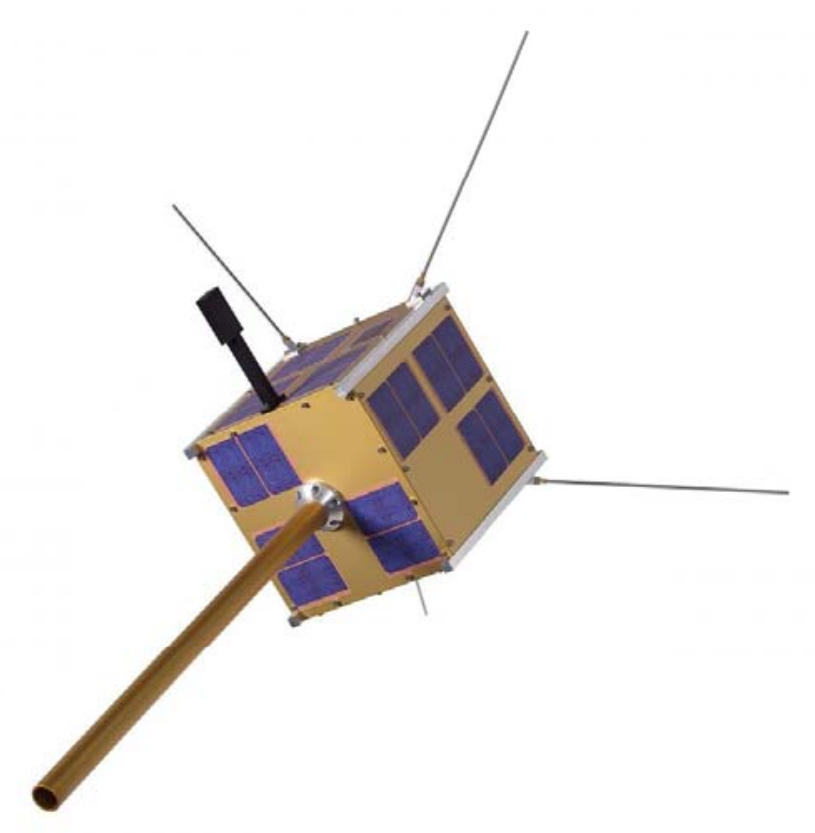




\section{Views on the Arctic, sea ice, and ship traffic}
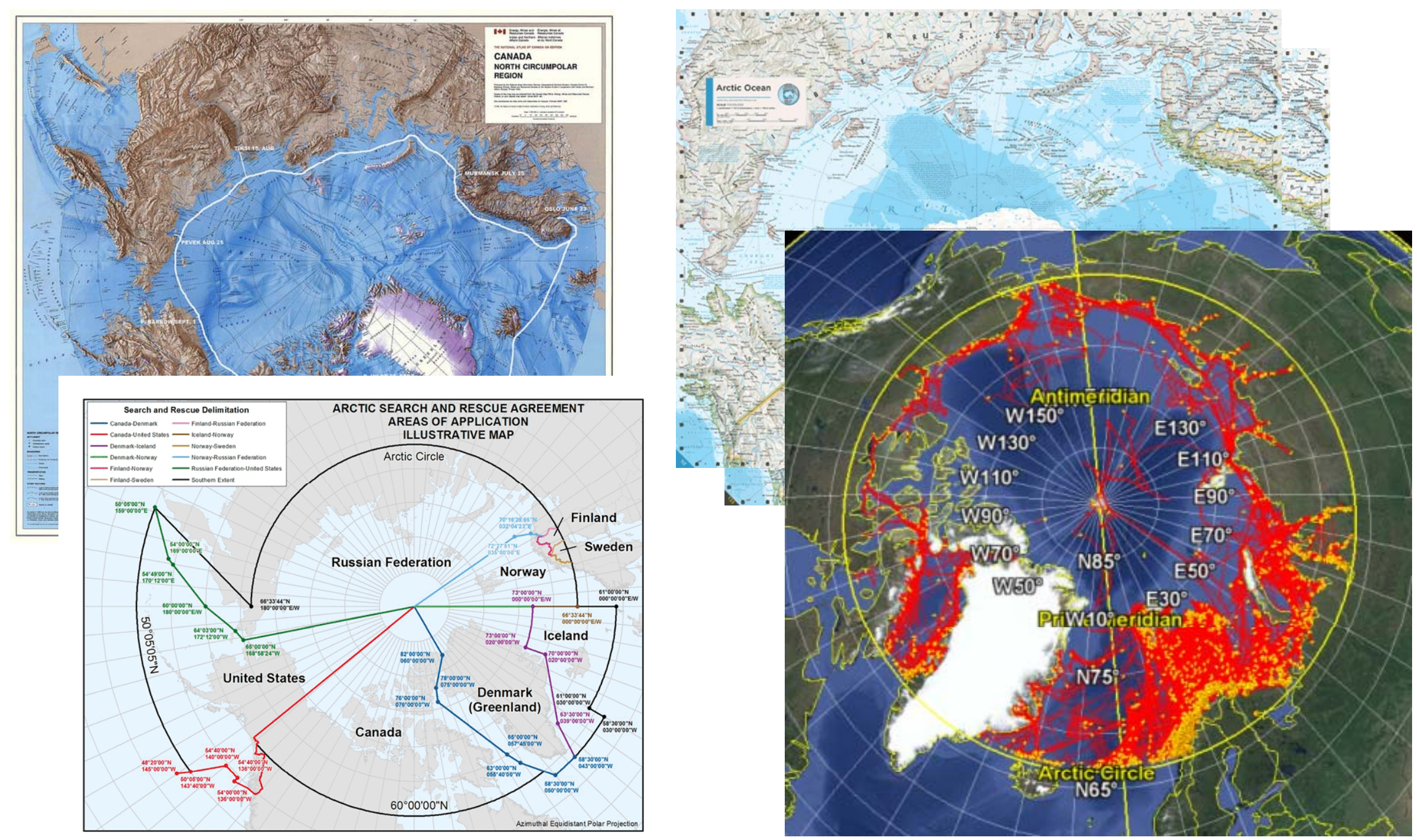


\section{Number of ships per month \\ - 5 years; class A, B, and total number of ships}

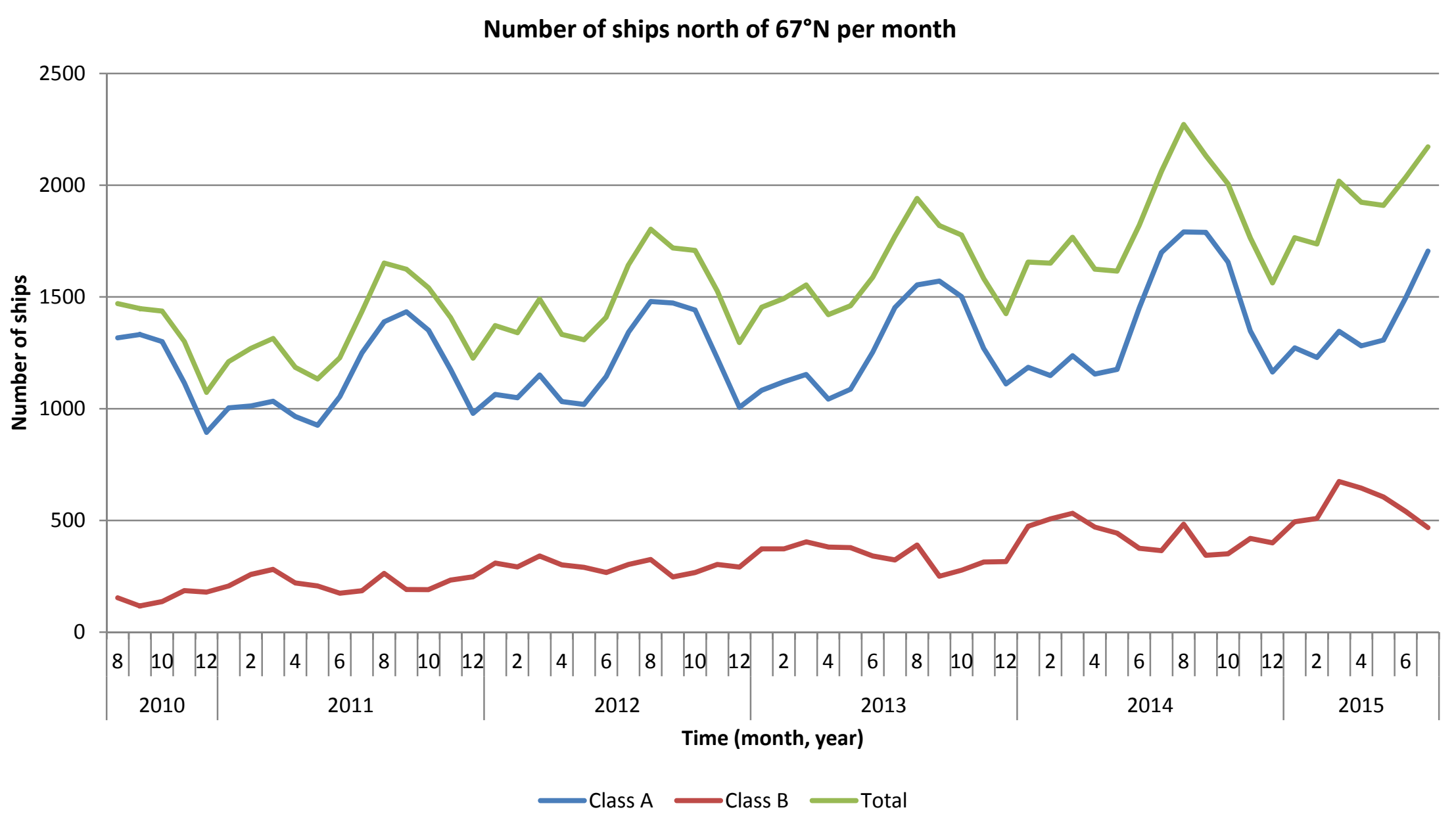




\section{Number of ships per month \\ - 4 years; monthly trend lines (August example)}

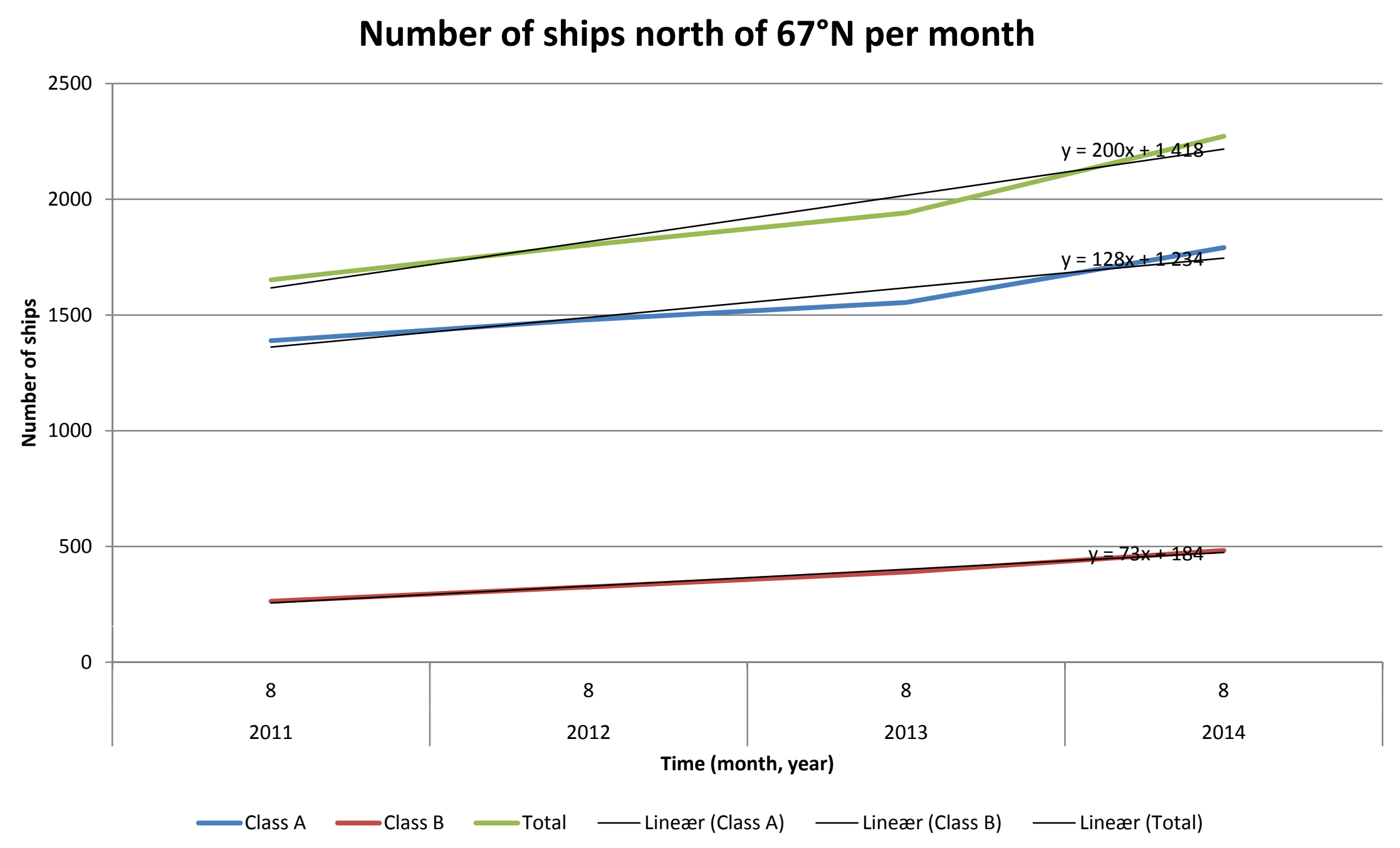




\section{Number of ships per month \\ - Average annual growth (from trend lines)}

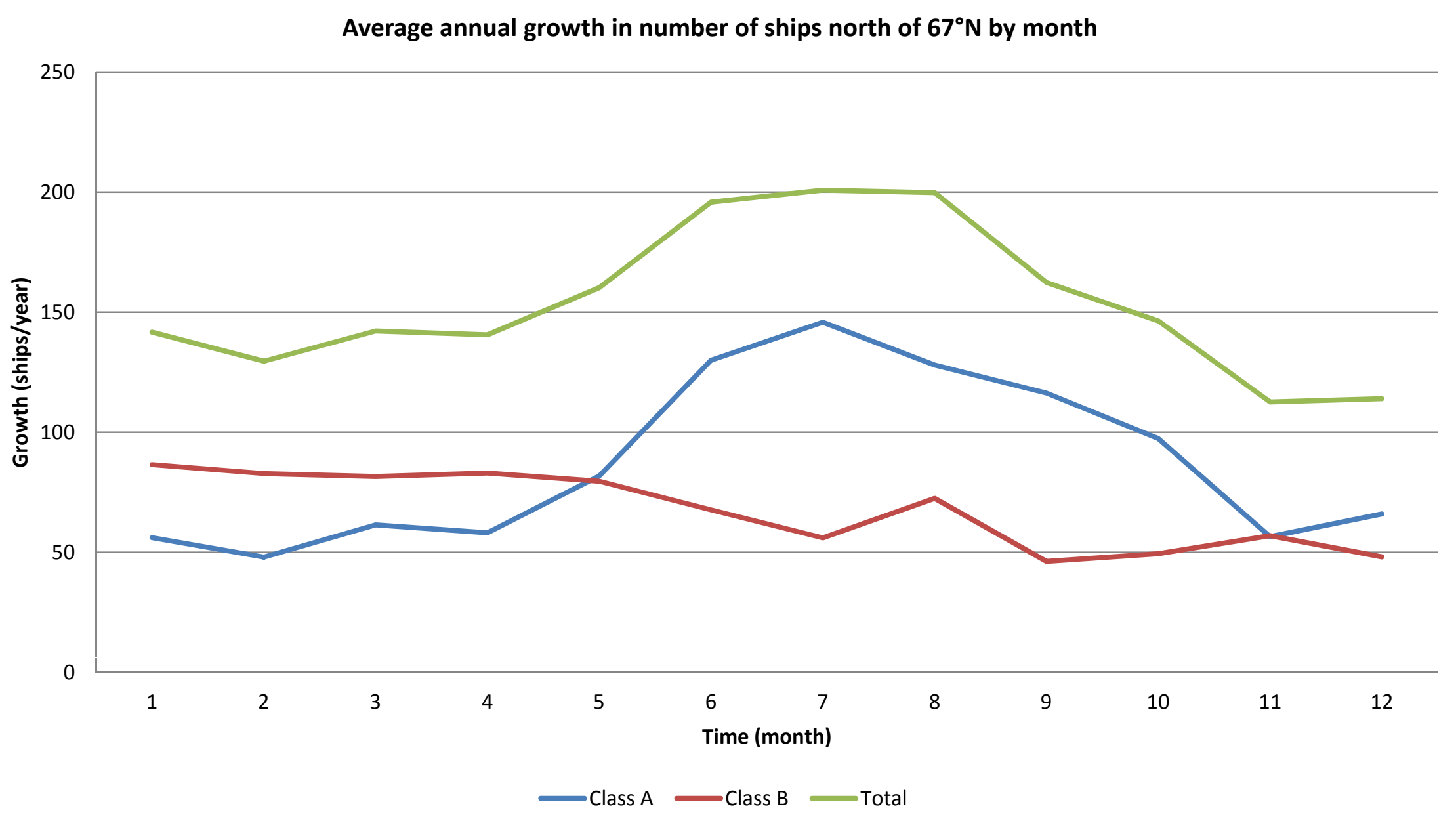




\section{Number of ships per month \\ - 2015; Observations and prediction intervals}

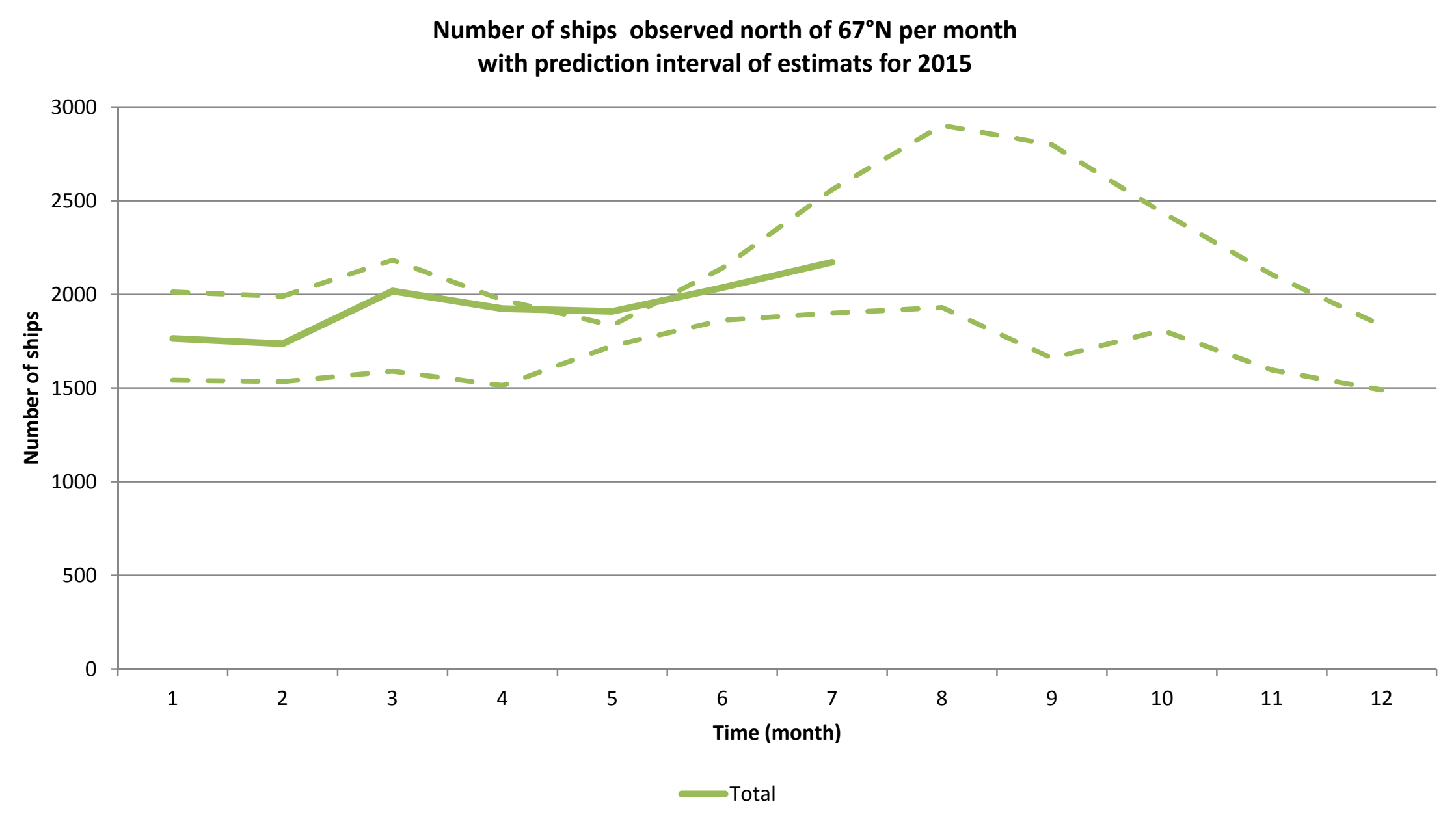




\section{Number of ships per month \\ - 2015; Observations and prediction intervals}

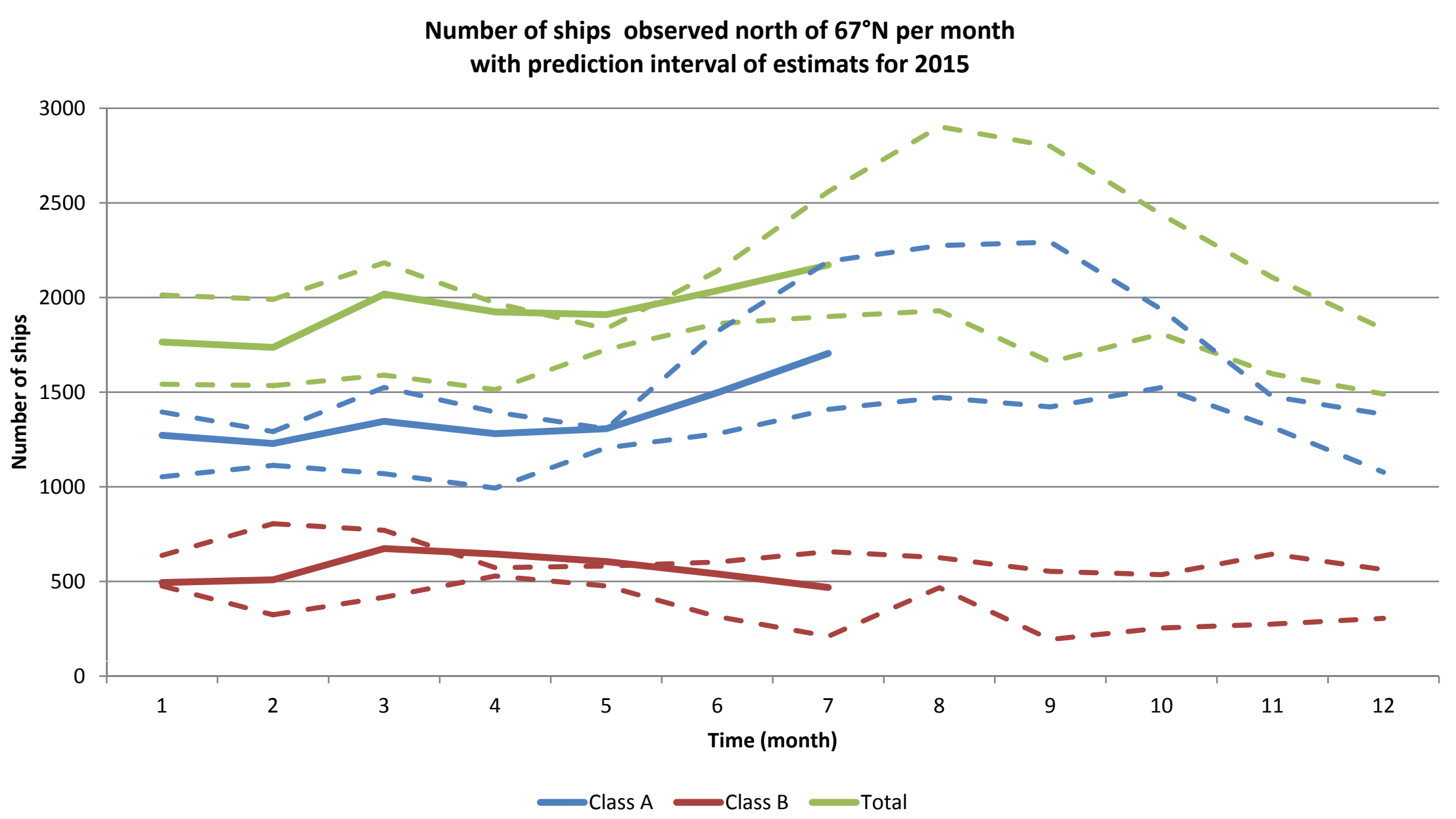




\section{Number of ships per month \\ - 5 years; by ship type}

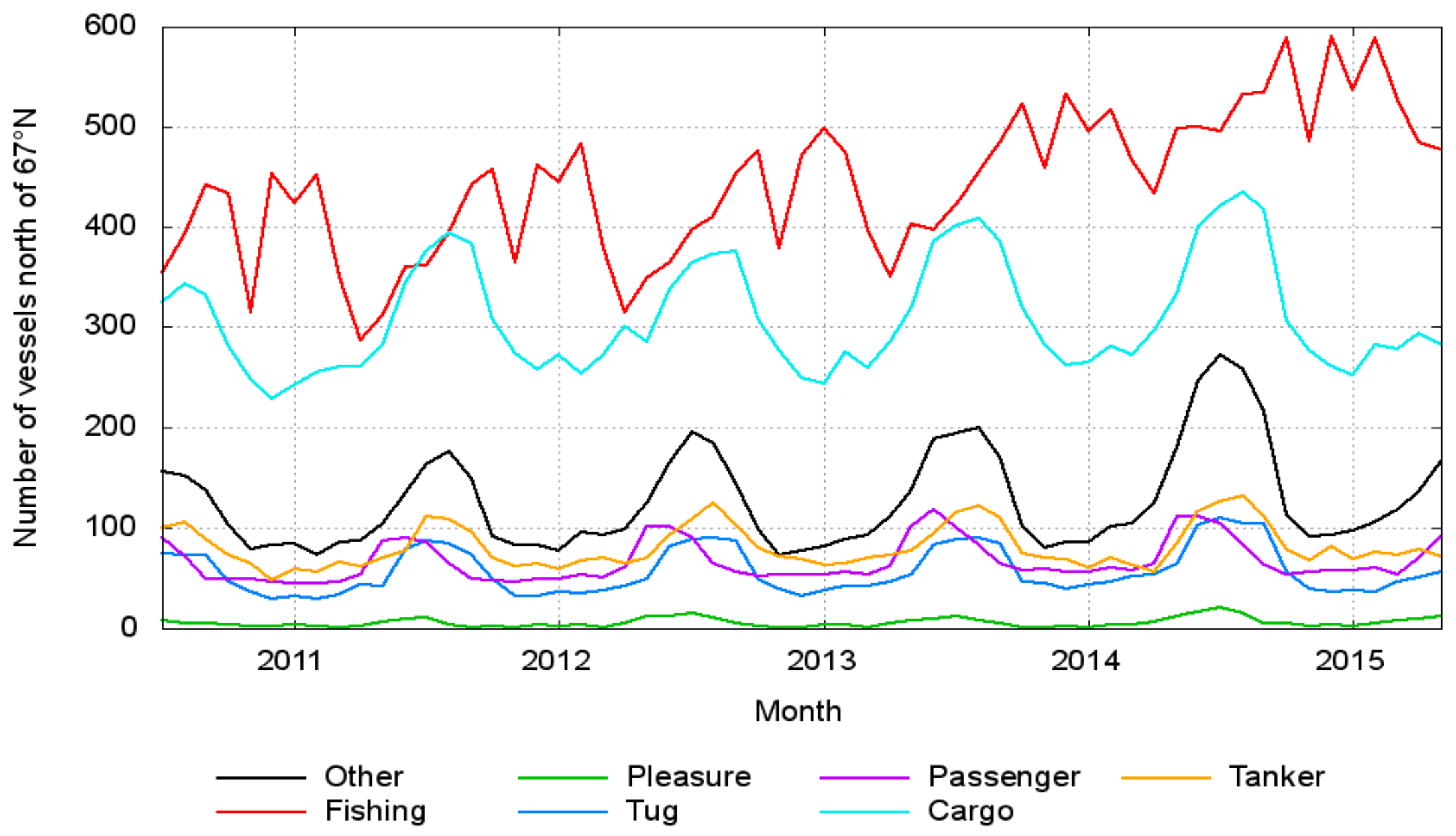

\section{$\mathbf{F F |}$ Forsvarets}




\section{Geographic distribution in $45^{\circ}$-Ion sectors - 5 years; total number of ships}

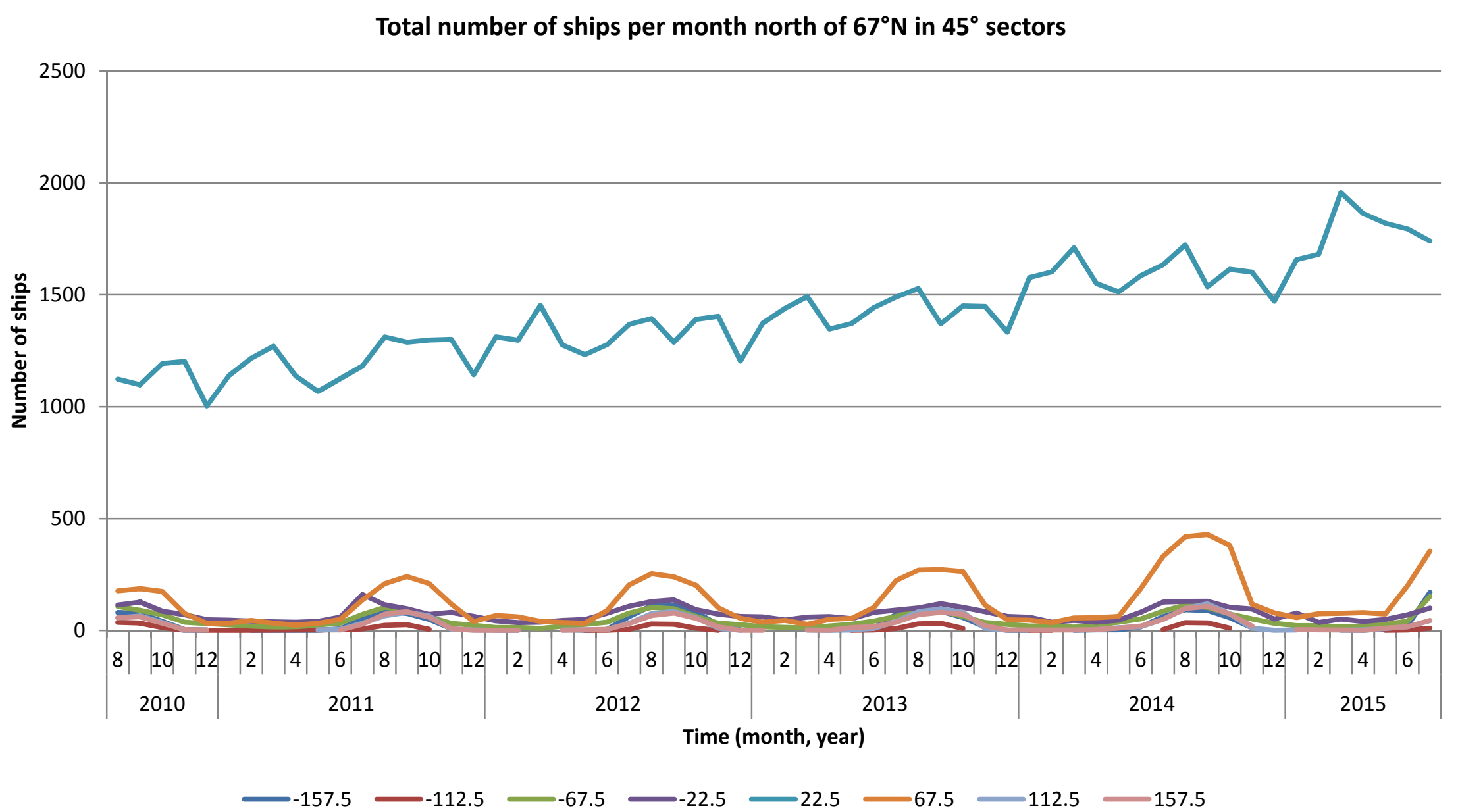




\section{Geographic distribution in $45^{\circ}$-Ion sectors - 5 years; total number of ships (zoom)}

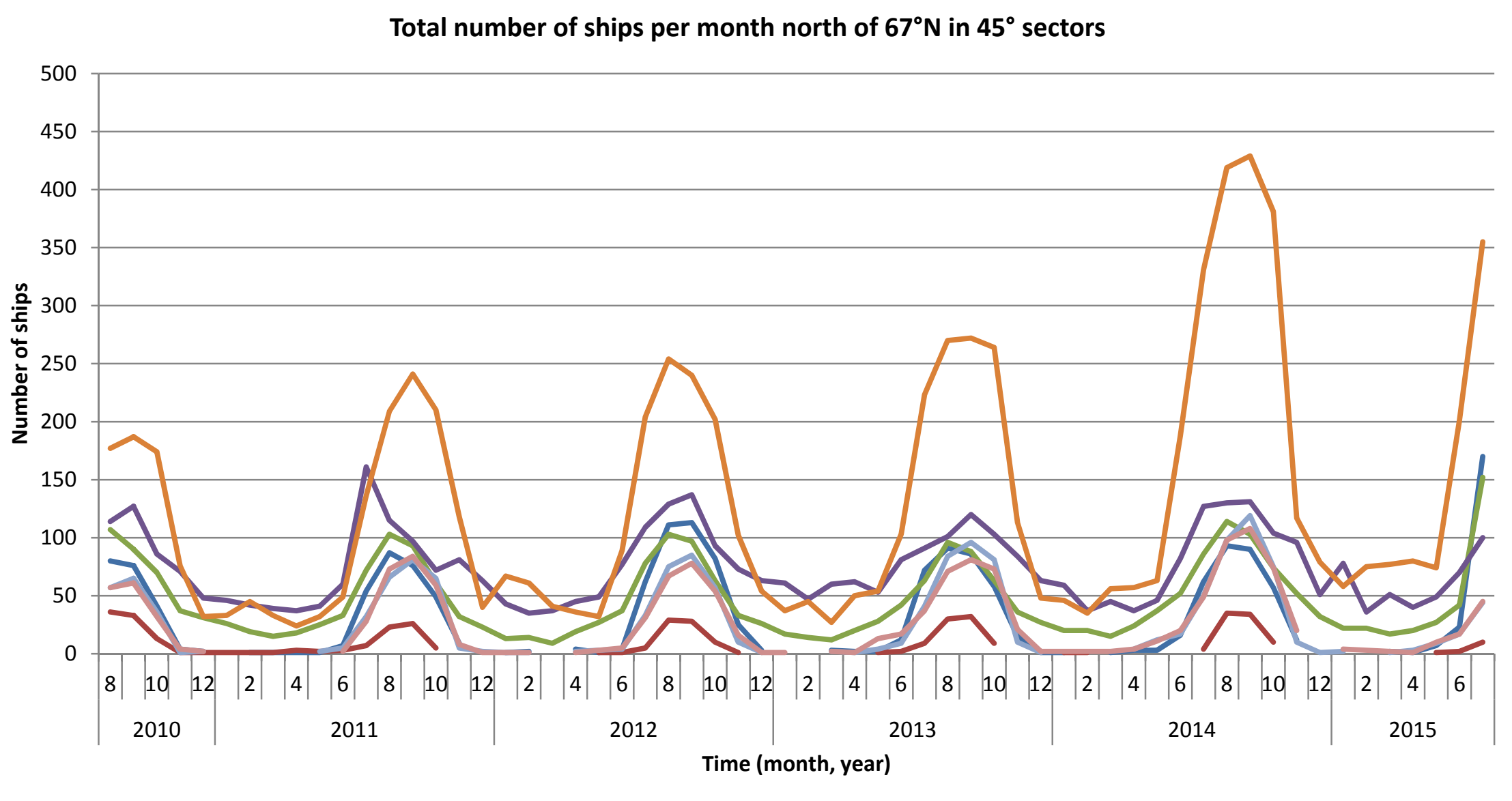

$-157.5-112.5-67.5-22.5-22.5-67.5-112.5-157.5$ 


\section{Geographic distribution in $45^{\circ}$-Ion sectors - growth in total numbers from 2013 to 2014}

\begin{tabular}{|l|r|r|r|r|r|r|r|r|r|}
\hline & -157.5 & -112.5 & -67.5 & -22.5 & 22.5 & $\mathbf{6 7 . 5}$ & 112.5 & 157.5 & Total \\
\hline Jan & 1 & 1 & 3 & -2 & 204 & 9 & 0 & 1 & 217 \\
\hline Feb & 0 & 1 & 6 & -10 & 163 & -10 & 1 & 2 & 153 \\
\hline Mar & -2 & 0 & 3 & -15 & 218 & 29 & -2 & 0 & 231 \\
\hline Apr & 1 & 1 & 4 & -25 & 204 & 7 & 3 & 3 & 198 \\
\hline May & 1 & -1 & 9 & -7 & 141 & 9 & 8 & -2 & 158 \\
\hline Jun & 4 & -2 & 10 & 1 & 142 & 85 & 8 & 3 & 251 \\
\hline Jul & -10 & -5 & 23 & 36 & 144 & 108 & 9 & 12 & 317 \\
\hline Aug & 2 & 5 & 18 & 29 & 195 & 149 & 14 & 27 & 439 \\
\hline Sep & 4 & 2 & 15 & 11 & 166 & 157 & 23 & 27 & 405 \\
\hline Oct & -1 & 1 & 11 & 1 & 164 & 117 & -6 & 1 & 288 \\
\hline Nov & -3 & 0 & 16 & 12 & 153 & 4 & 0 & -1 & 181 \\
\hline Dec & -1 & 3 & 5 & -12 & 138 & 31 & 0 & -2 & 162 \\
\hline Total & -4 & 6 & 123 & 19 & 2032 & 695 & 58 & 71 & 3000 \\
\hline
\end{tabular}




\section{Geographic distribution in $45^{\circ}$-Ion sectors - growth in total between 2011 and 2014}

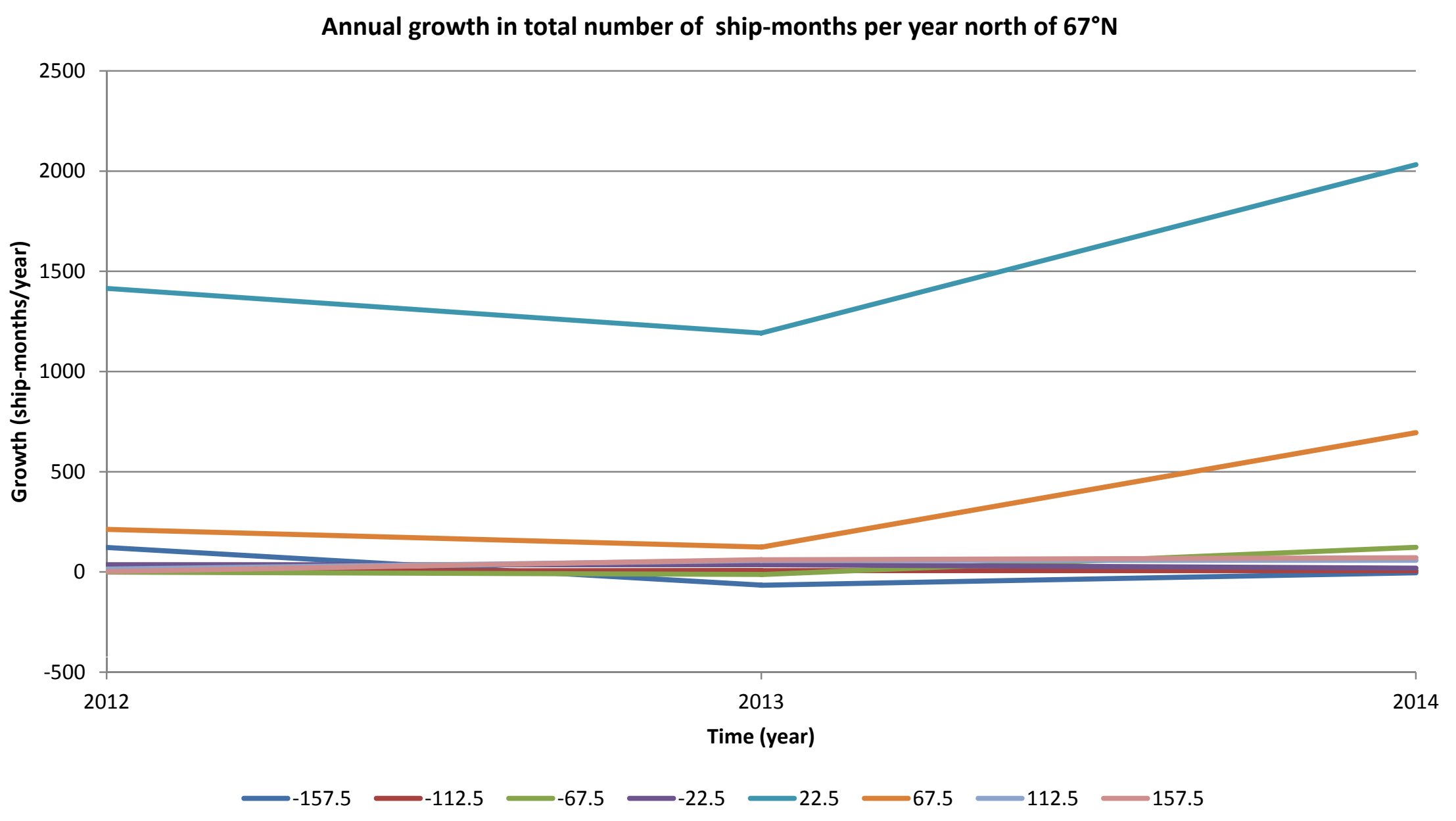




\section{Geographic distribution in $45^{\circ}$-lon sectors - growth in total between 2011 and 2014 (zoom)}

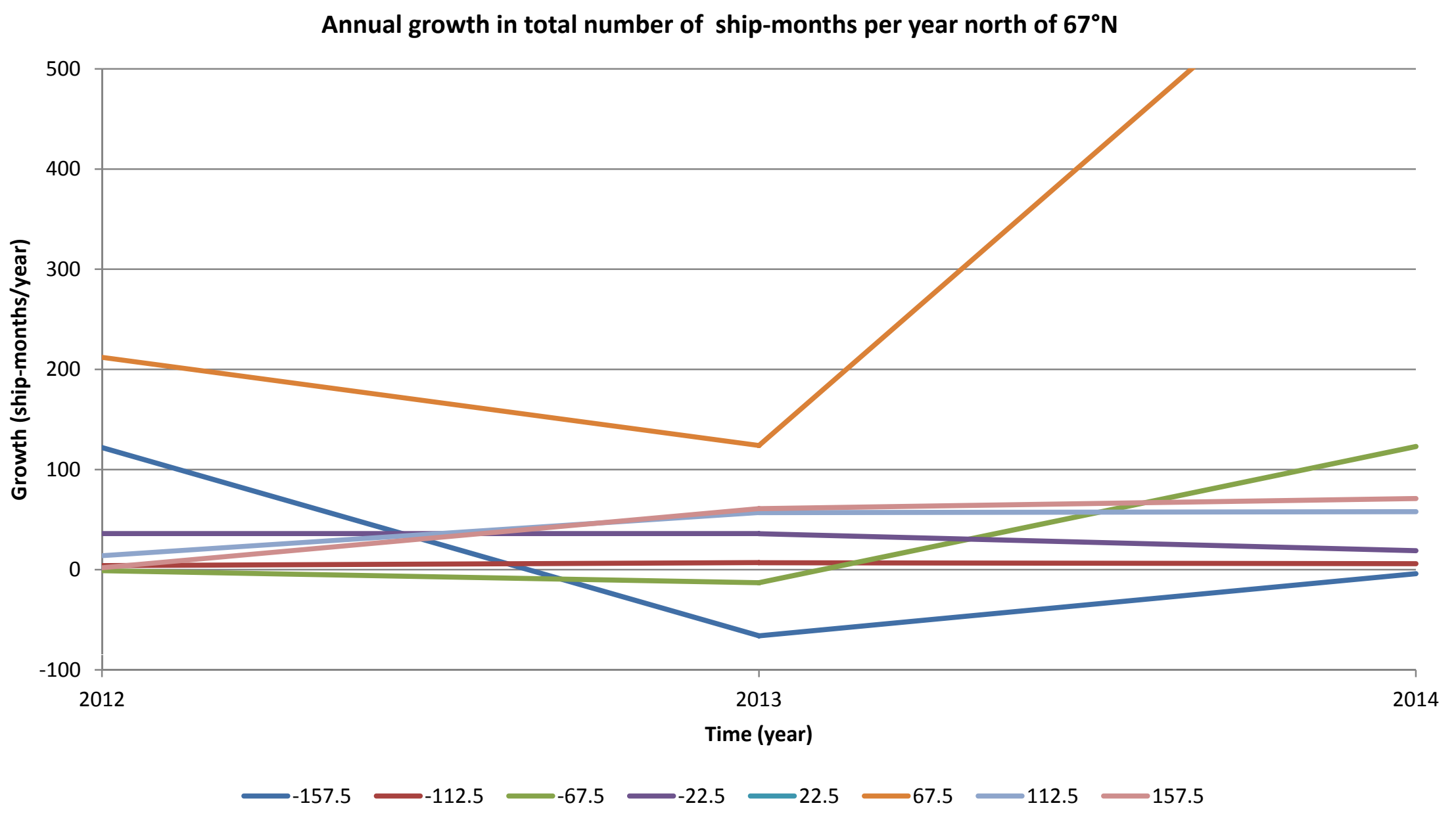




\section{Geographic distribution in $45^{\circ}$-Ion sectors - relative growth in total between 2011 and 2014}

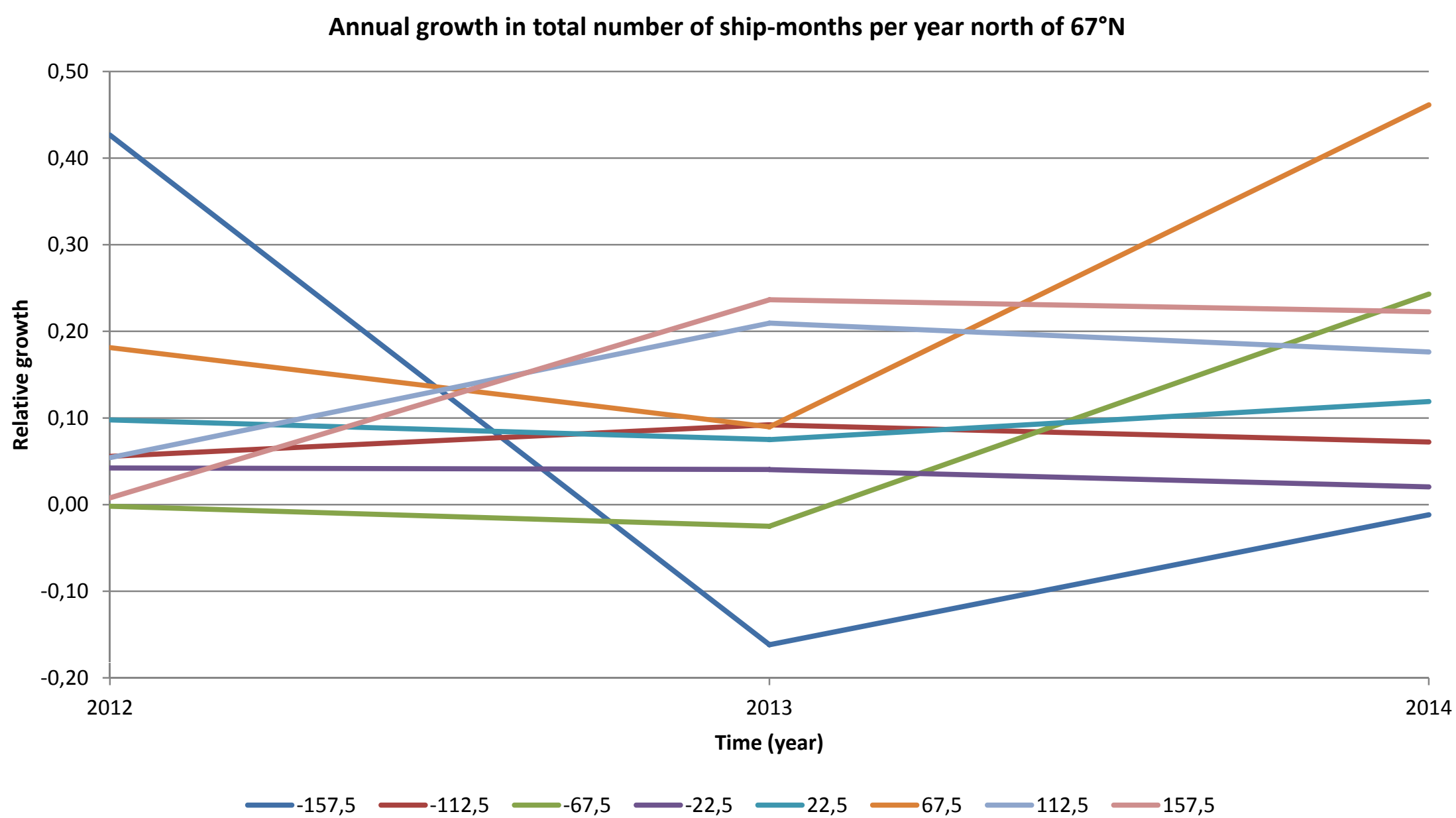




\section{Number of ships counted by flag state - August 2014 in the entire Arctic north of $67^{\circ} \mathrm{N}$}

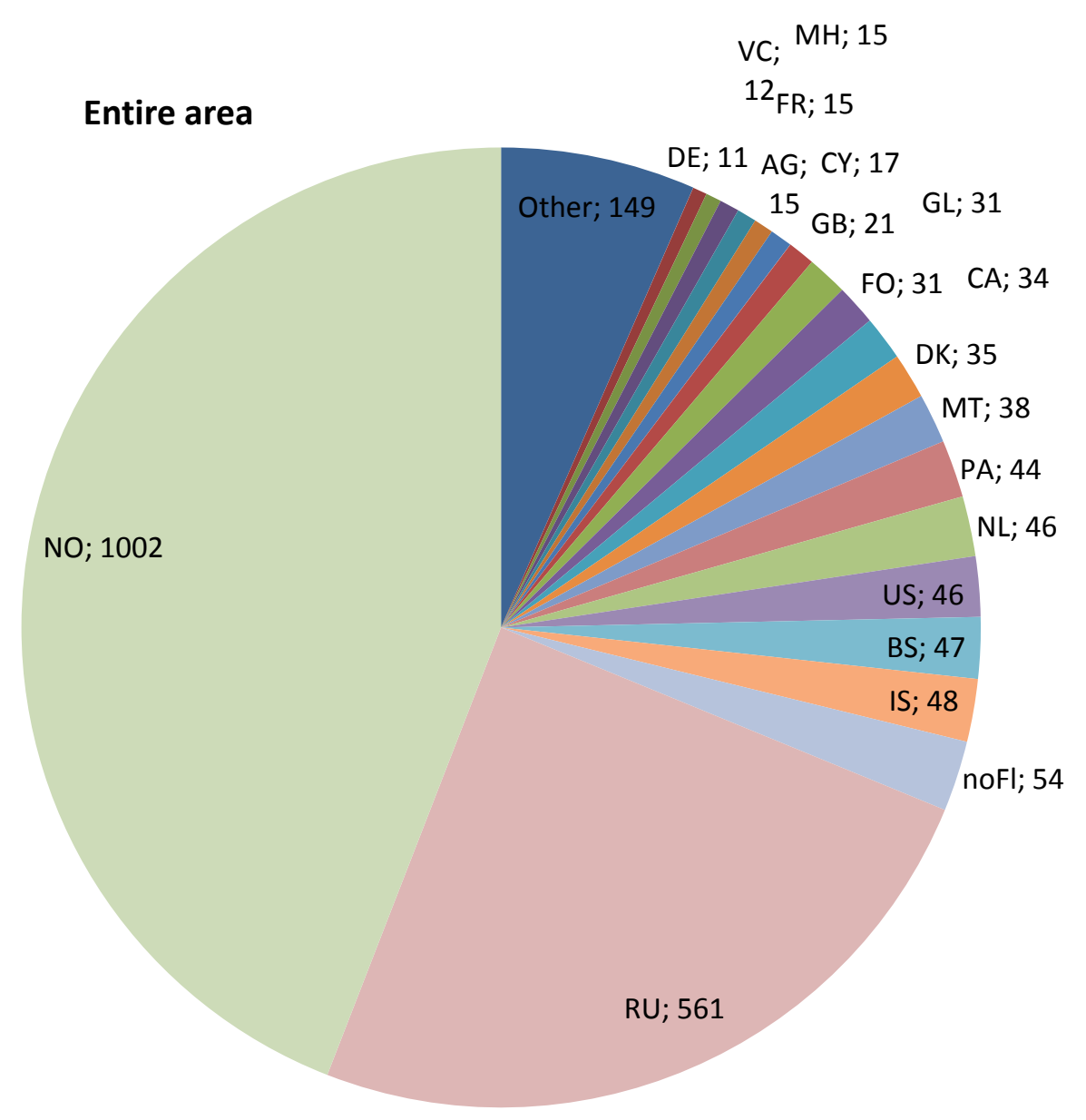




\section{Number of ships counted by flag state}

- August 2014 in sectors of $45^{\circ}$ longitude

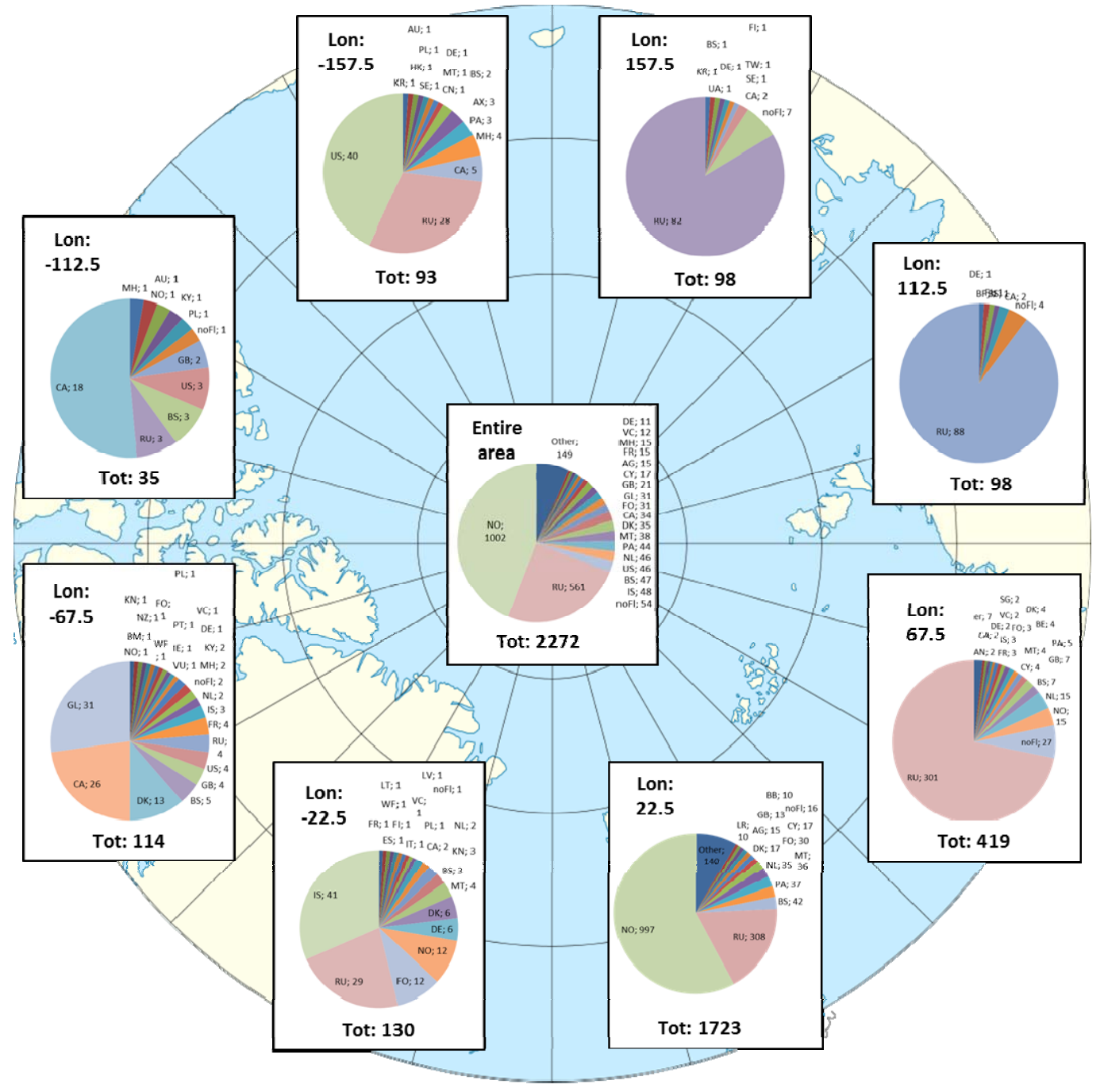




\section{Ships crossing the Northeast Passage}

- 5 years; Count of ships per month

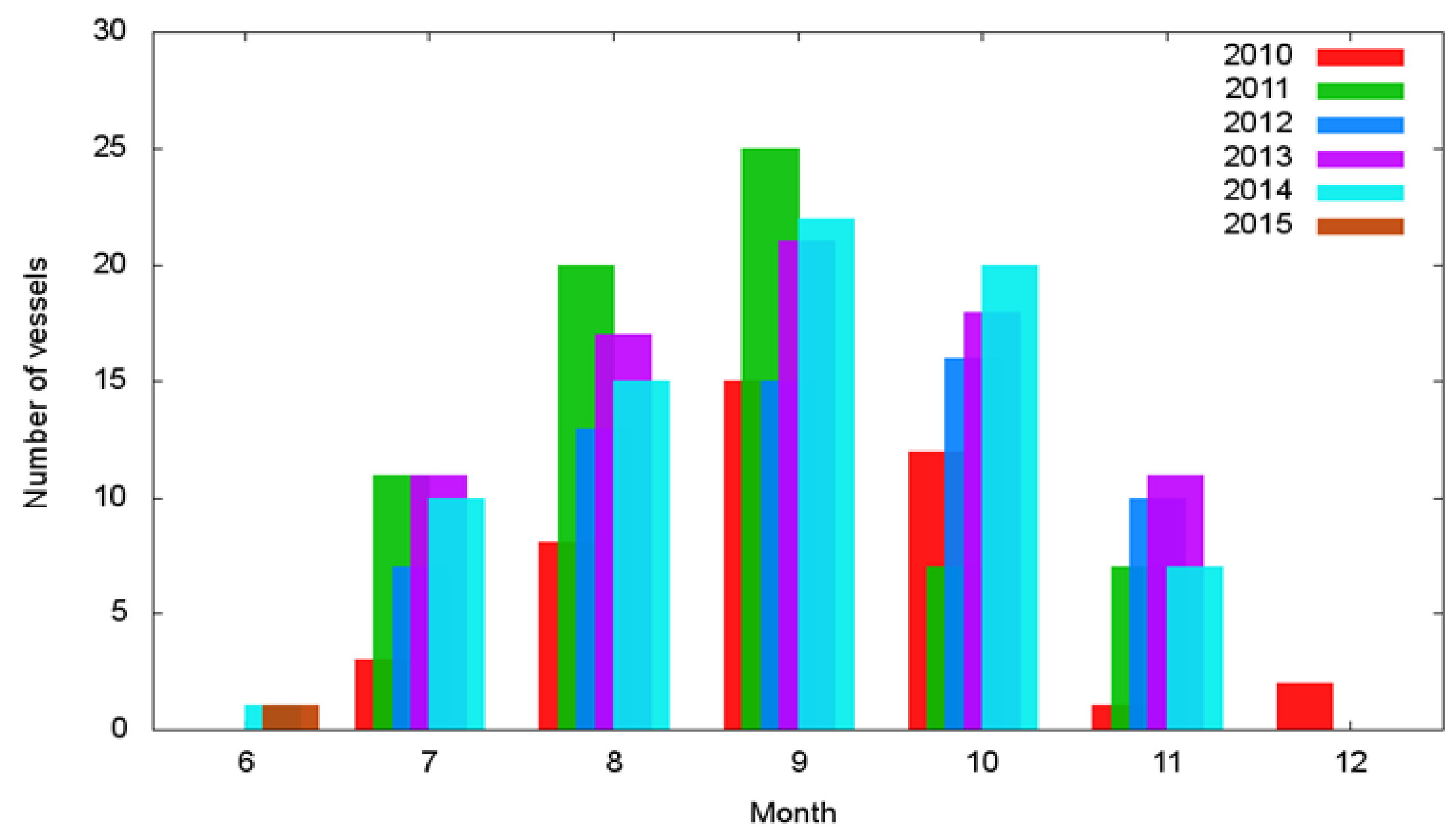




\section{Ships crossing the Northeast Passage - 5 years; Total ship-months with uncertainty}

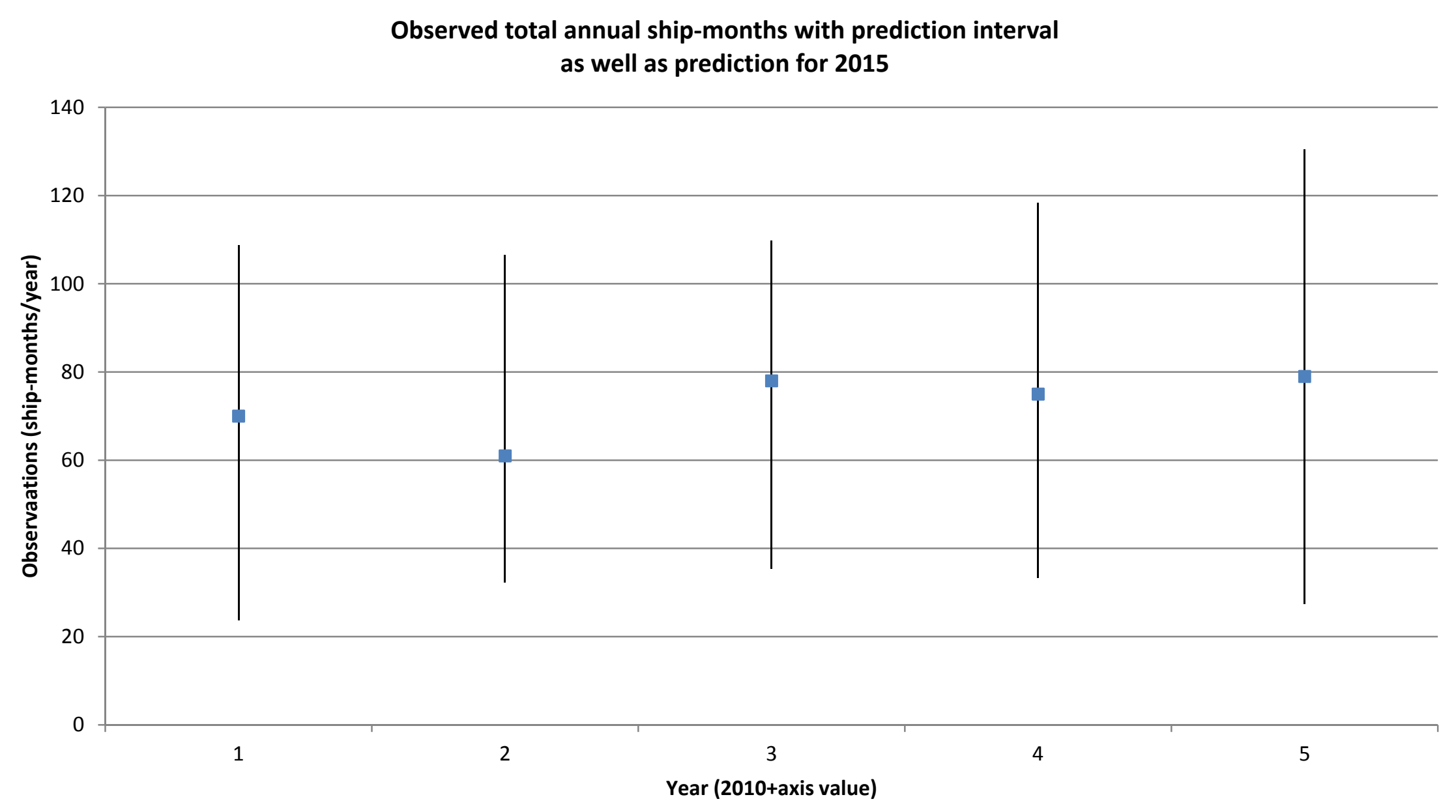




\section{Seasonal variations in ship tracks}
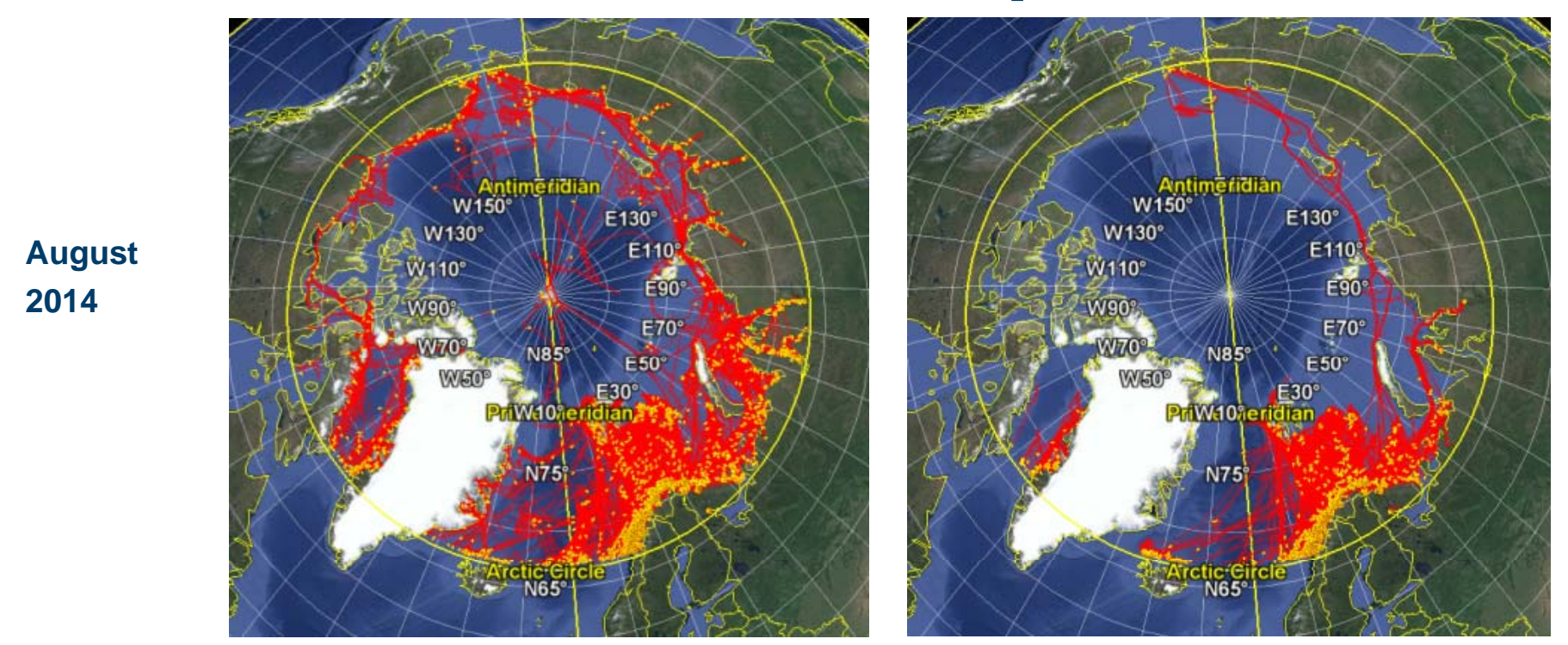

November

2014

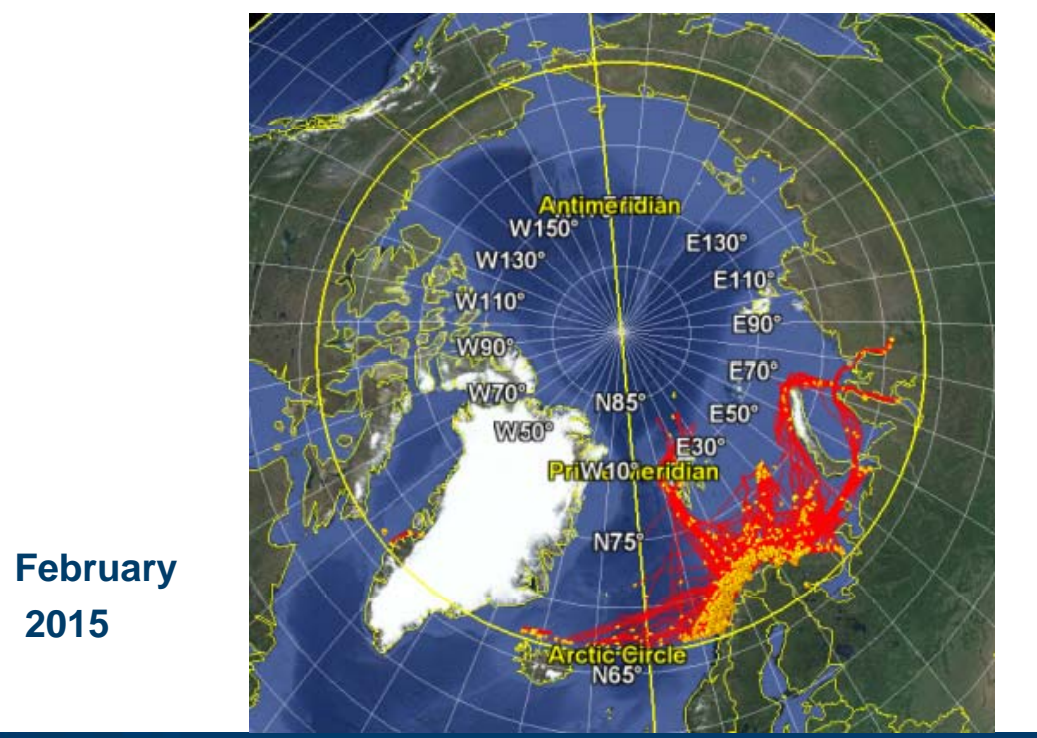

FF| Forsvarets

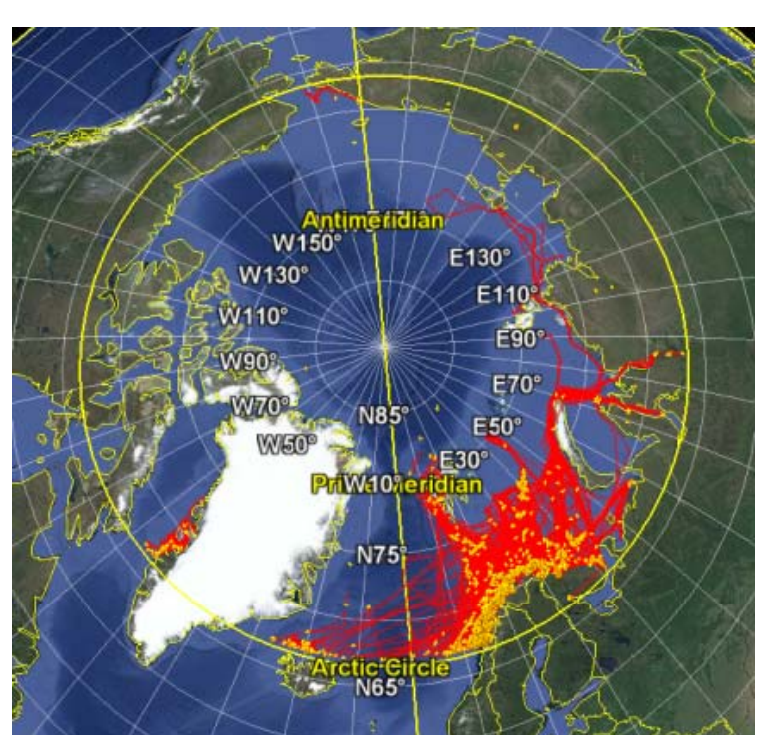

May

2015 


\section{Annual ship densities in July 2011 - 2014}
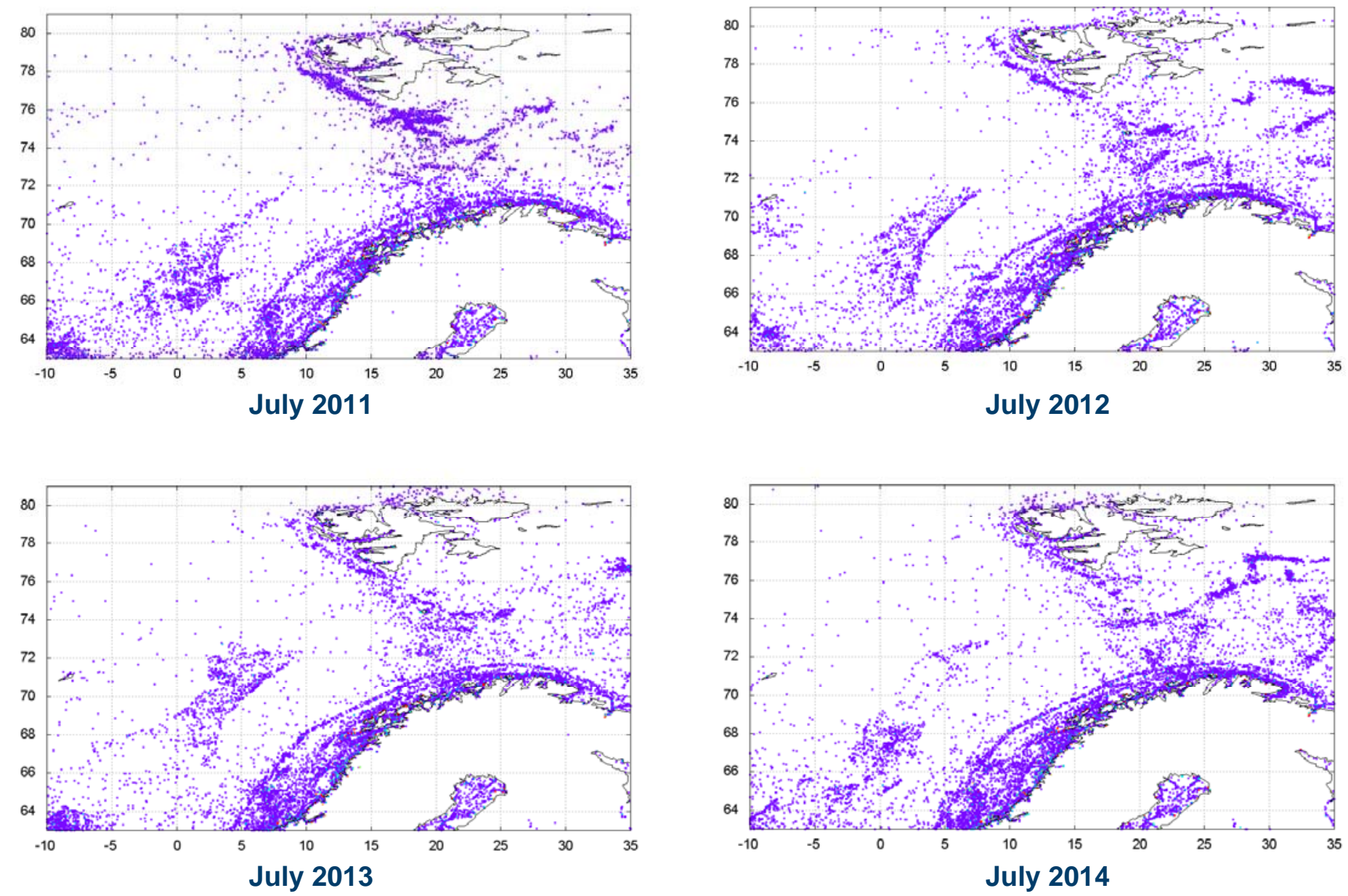


\section{Ship tracks on 14 August 2014}

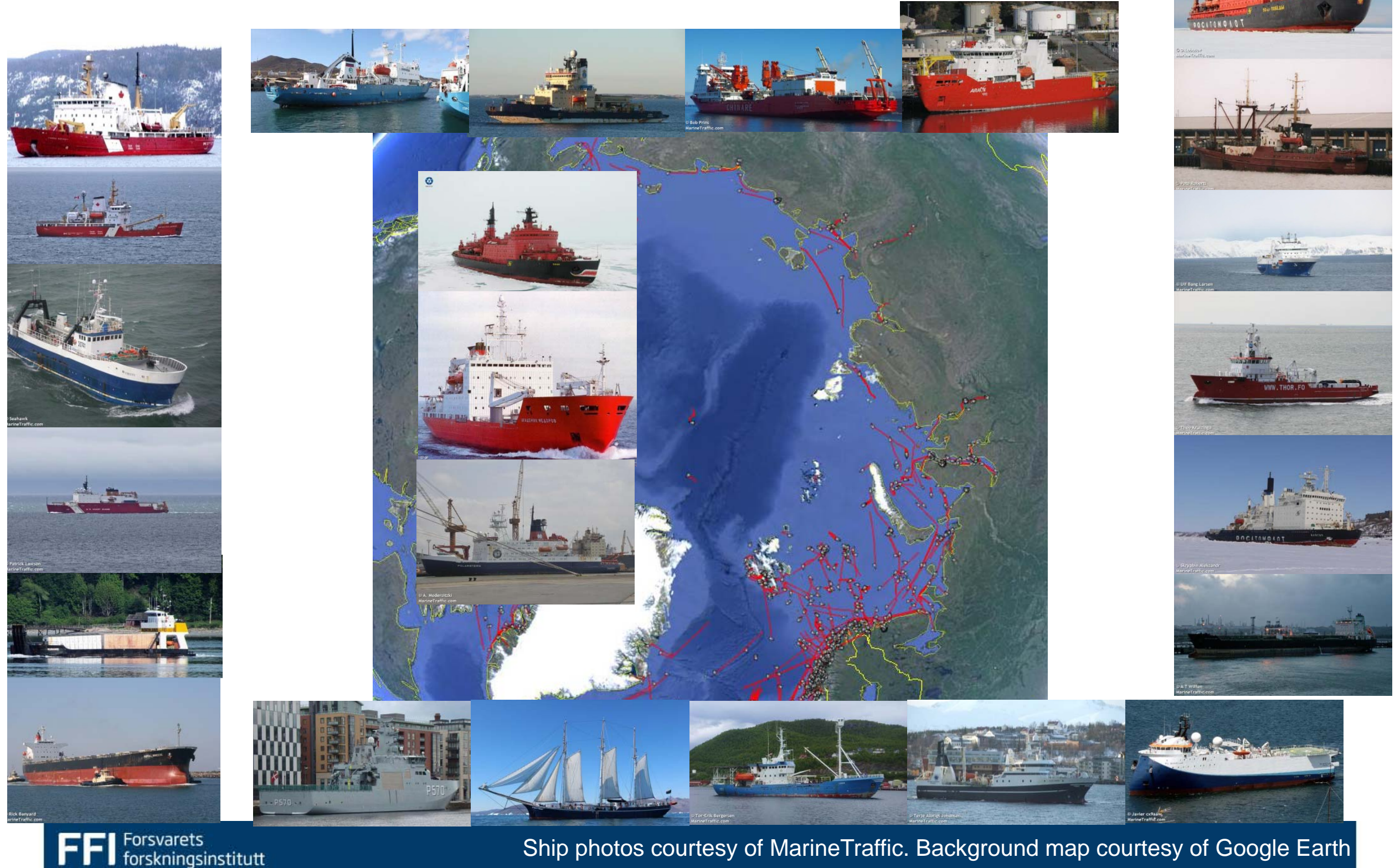




\section{Ship positions coloured by the number of observations for each ship}

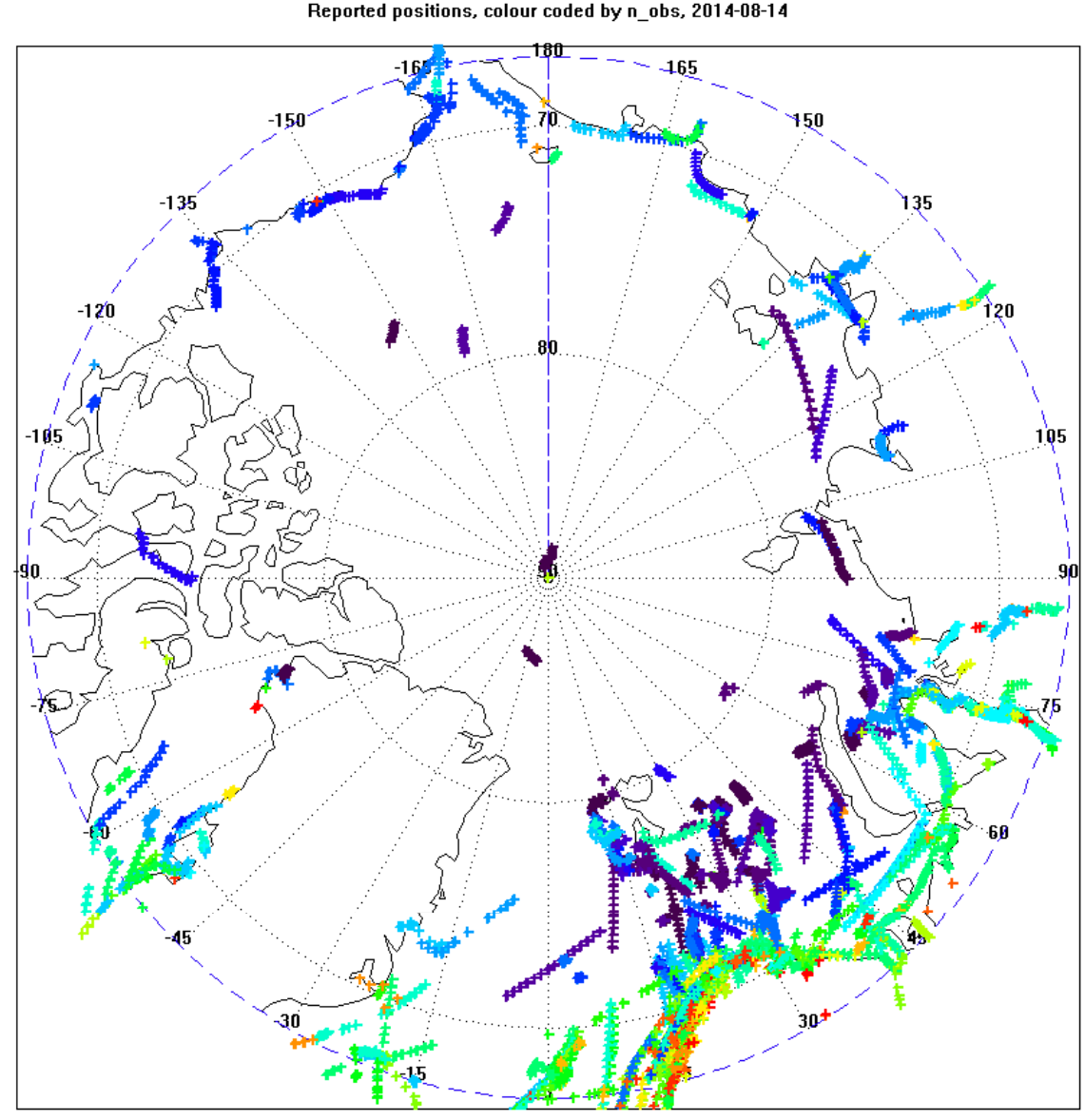

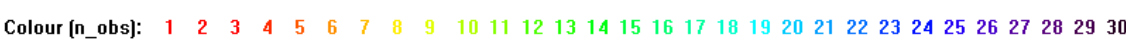




\section{Quality of service parameters distributions}
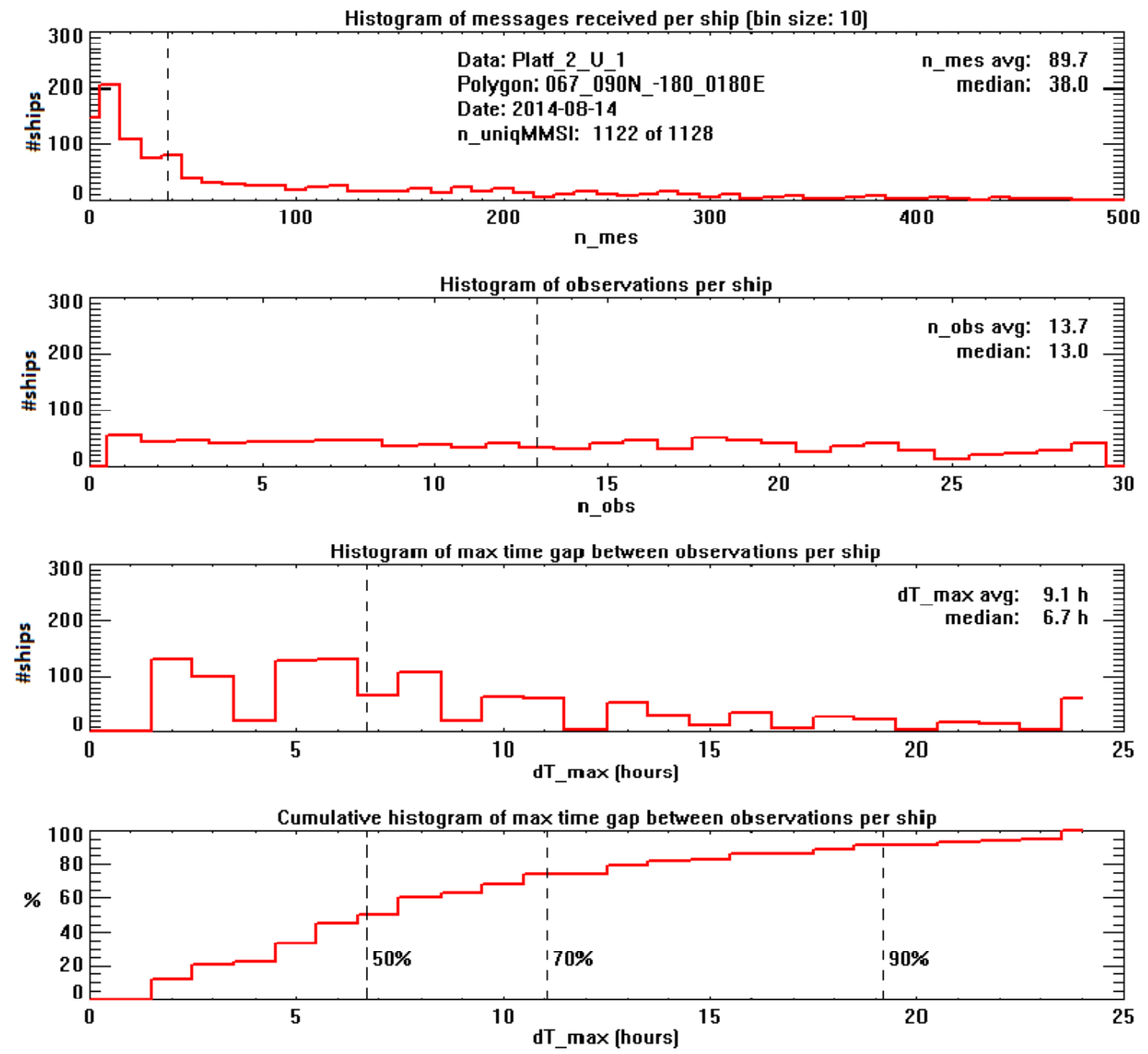

\section{$\boldsymbol{F F} \mid \begin{aligned} & \text { Forsvarets } \\ & \text { forskningsinstitutt }\end{aligned}$}




\section{Summary}

- The number of reporting ships per month has varied from 1073 (December 2010) to 2272 ships (August 2014).

- The growth in number of reporting ships varies with month; from 113 at the minimum in November to 201 ships/year at the maximum in July.

- The growth is partly due to changes in regulations, i.e. EC 1224/2009 (the Control Regulation) by 31 May 2014 all fishing vessels above 15m.

- The highest number of ships are in the $0-45^{\circ} \mathrm{E}$ sector, 1723 of 2272 ships in August 2014. The annual growth has been around 10\%.

- The highest relative growth is in the following three eastern sectors, having an average growth between $15 \%$ and $24 \%$ per year.

- Monthly ship-type counts give 600 fishing vessels, 430 cargo ships, 120 tankers, 100 passenger ships, 100 tugs and 280 other ships (in 2014).

- Up to 1200 vessels are observed per day, of which 1100 are using AIS Class A and 100 Class B.

- The median number of position updates per ship per day are typically 13 and the largest daily time gaps are smaller than 6.7 hours. 


\section{Number of ships counted by flag state - August 2014 by sector}

Number of vessels v.s. month and flag in the sectors Class A, August 2014

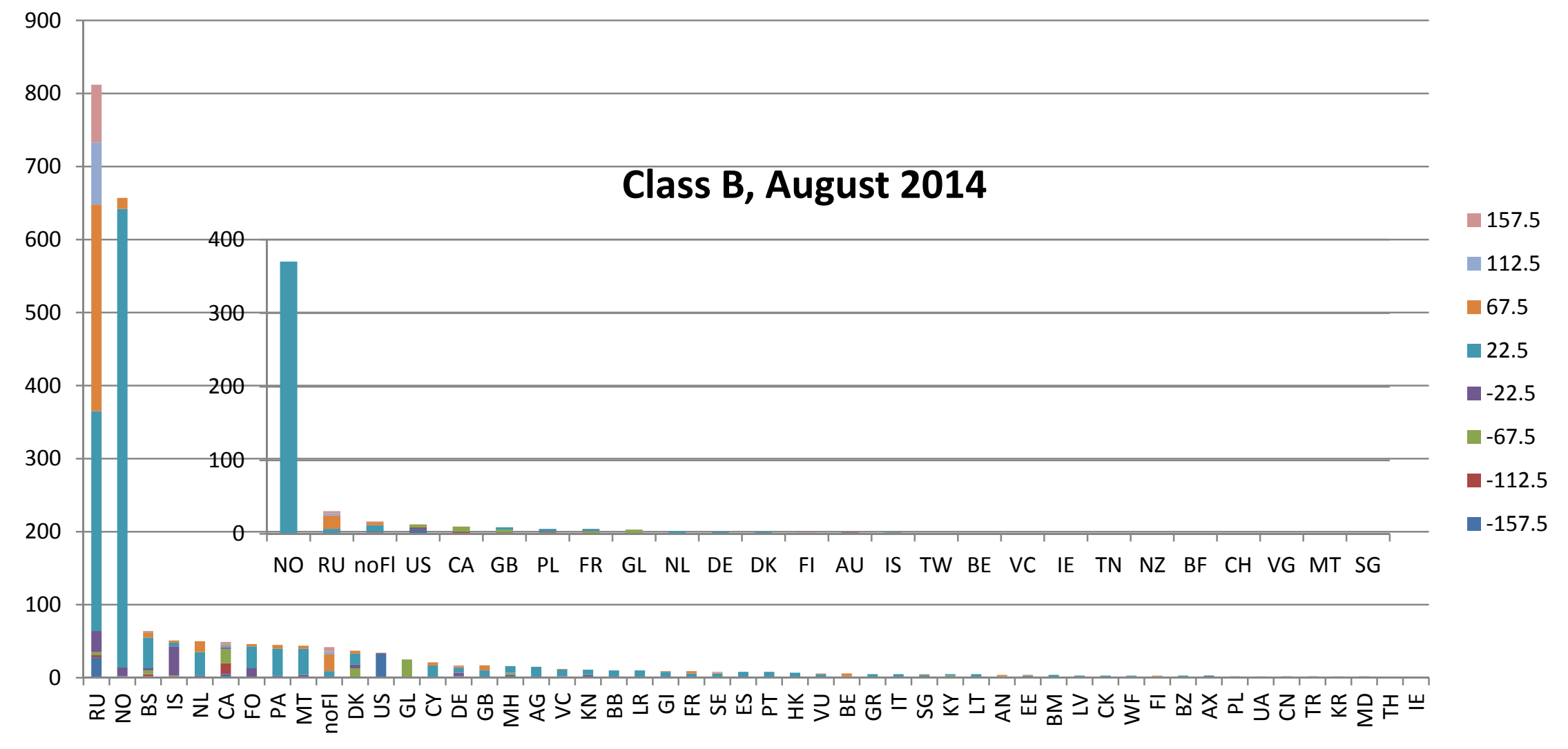

